\title{
Clausura: universalidade desconhecida
}

\author{
Francielly Baliana (USP)* \\ https://orcid.org/0000-0001-8488-2757
}

\section{Resumo:}

Este texto trata da clausura. Justamente por isso, em nada parece se diferenciar dos demais. Como qualquer outra textualidade - submetida ao jogo de significação da autoria, da forma, do conteúdo -, talvez seja uma manifestação possível dos saberes que o encerro produz. Quem sabe seu diferencial esteja em aceitar que suas contingências produzem sua própria significação. Jacques Derrida contribui com a hospitalidade a outros autores, como Roberto Bolaño, Diamela Eltit e Giorgio Agamben. De diferentes formas, todos parecem anunciar questões sobre a clausura. Essas percepções não esgotam a questão, mas apontam para o percurso escorregadio de qualquer significado. Este texto, portanto, é sobre incertezas, ou sobre a clausura das certezas. Este texto é, melhor dizendo, sobre a importância de uma incerteza responsável.

Palavras-chave: Clausura; Jacques Derrida; Universidade; Literatura.

\section{Abstract:}

\section{Enclosure: unknown universality}

This text is about the enclosure. Precisely for this reason, in no way does it appear to be different from the others. Like any other textuality - submitted to the game of signification of authorship, of form, of content -, perhaps it is a possible manifestation of the knowledge that the closure produces. Maybe its differential is to accept that its contingencies produces their own significance. Jacques Derrida contributes with the hospitality to other authors, such as Roberto Bolaño, Diamela Eltit and Giorgio Agamben. In different ways, they seem to announce questions about the enclosure. These perceptions do not exhaust the issue, but point to the slippery path of any significance. This text, therefore, is about uncertainties, or about the closure of the certainties. This text is, rather, about the importance of responsible uncertainty.

Keywords: Enclosure; Jacques Derrida; University; Literature.

* Mestra em Letras pela Universidade Federal de São Paulo e Doutoranda em Teoria Literária e Literatura Comparada pela Universidade de São Paulo. E-mail: bg.francielly@gmail.com 
Agosto de 2020. Olho para o calendário. Mais de 150 dias de clausura. A repetição marca a singularidade? Assino novamente o mesmo percurso. A virtualidade. Dou aula para uma câmera. Assisto a aulas sem que me vejam. A presença. A espectralidade. Os espectros de Derrida e da universidade. Minha tese é um texto enclausurado e minha condição é o encerro. A forma encontra seu sentido, encena suas veias, acende seus receios. Falar da clausura, na clausura. Onde é o fora? Quem é o fora? Multidões de pessoas pertencem agora ao fora. Umas escolhem. Outras não. Um texto começa só.

Alguém com uma câmera de celular na mão filma algumas pessoas sentadas em cadeiras na calçada de um bar no bairro do Leblon, anunciando a felicidade por sair da clausura, depreciando a crença na letalidade do vírus. Seu rosto não aparece. Os frequentadores do local são mulheres e homens brancos, em sua maioria ou em sua totalidade. A inexatidão da métrica se confirma pela pequena amostragem, que foca em mais ou menos três metros quadrados do metro quadrado mais caro da América Latina. As pessoas estão bem próximas, sem máscaras, em julho de 2020, mês que precedeu aquele em que o Brasil firmou sua posição de segundo país do mundo com mais mortes por COVID-19, ao completar os 100 mil casos. As praias de setembro ainda não eram notícia. Um texto só começa. Os garçons estão de máscara. Os entregadores de comida estão de máscara. Um quadro da Tarsila é repintado com operários de máscara. Uma moradora em condição de rua morre de frio. Cinquenta cachorros devem agora estar à beira da morte. Em seus apartamentos de 45 metros quadrados, pessoas morrem de calor. Assumo que quero voltar para a cama. Um curso sobre Derrida com meu orientador. Uma turma de mais ou menos 45 pessoas.
Mais ou menos 28 compareceram à modalidade virtual. Às vezes, 29 estavam online. Cinco pessoas falavam. Três mantinham a câmera aberta. Às vezes quatro. Sinto muito, disse uma aluna. Um pedido de desculpas ou uma confissão? A metafísica da presença. Quase peço por uma origem que marcasse o real, a verdade, o sentido. Adentramos o meio-termo, a terceira via. 0 virtual é quase. O quase é sempre um estranhamento. E o estranho é, no mais profundo, familiar. Está tudo bem, disse a professora. A professora sou eu. A aluna também.

Um texto começa só. A frase contém em si a possibilidade própria da dúvida, da negação, da afirmação de que um texto não começa só. Ao se apropriar de palavras que em suas particularidades convoquem sentidos mais ou menos estabilizados, a ideia de que um texto começa só obrigatoriamente carrega a ideia de que um texto é a junção de palavras, que por si só também são textos. Um texto nunca poderia, assim, começar só. Um texto parece justamente a impossibilidade de um acontecimento solitário. Um texto só começa. A simples troca sintática revela que a estrutura da frase movimenta suas próprias ilusões de unicidade, traduzindo um pouco da possibilidade de que um texto nunca termina, posto que estaria eternamente afetando e sendo afetado pelas atribuições de sentido, pelos jogos de invenção e de forma, pelas contingências de seus próprios começos. Poderíamos insistir nessa brincadeira para dizer também que: "um só texto começa"; "só um texto começa"; "só começa um texto"; "só texto um começa"; "só texto começa um". No último caso, "só texto começa um", se apelássemos para o "uno" do espanhol, cuja forma masculina recorrentemente significa "alguém", "uma pessoa", outros contornos um pouco mais próximos da ideia 
de sujeito passam a ocupar o campo desse jogo hermético de indecisões sobre como começar alguma coisa.

Como começa(r) alguma coisa? Onde começa(r) alguma coisa? Quando começa(r) alguma coisa? Por que começa(r) alguma coisa? Tais reflexões, a priori filosóficas, acabam por dançar sobre os limites das concepções de modo, de tempo e também de espaço, mas a escrita enquanto acontecimento parece carregar consigo todas essas perguntas. Ao ser transportada enquanto materialidade textual, é supostamente capaz de garantir a oportunidade da presença - do indivíduo que a assinou ou dos possíveis sentidos que sua textualidade, a partir das palavras, carrega -, indo além do tempo -espaço do ato em si de escrever.

Jacques Derrida, ao refletir sobre as relações entre escrita, fala e presença, afirma que a ideia de um sentido que preexista a alguma coisa que sirva a ele como significante é a condição da ideia de verdade em uma perspectiva ocidental. Em Gramatologia (2008), já esboçava o quanto essa ilusão de uma presença que preexiste ao texto, que também pode ser a voz ${ }^{1}$, configura uma soberania do significado em relação ao próprio significante, e desfazê-la é como criar uma espécie de cadeia de significantes, implicando a desconstrução da própria ideia de signo. Continuar a olhar para o signo, na ausência de um significado, é já iniciar um percurso desviante, um começo sem começo absoluto.

Apesar das acusações a respeito de um suposto niilismo em suas perspectivas analíticas, ao questionar os fundamentos externos e imperativos que formam o processo

1 Essa perspectiva, para Derrida (2008), instaura uma lógica ocidental fonocêntrica, que coloca a voz como mais confiável que a escrita, mais autêntica, por estar mais próxima e supostamente depender da presença. de significação da linguagem principalmente a partir de Gramatologia, Derrida contribui para tensionar o modo como as relações éticas e sociais se constroem. Os processos de significação, ao estarem imbricados ao texto, acabam por estar sujeitos ao próprio contexto de produção, de leitura, de recepção, de propagação dessa materialidade. A aceitação de uma significação preexistente seria a aceitação de uma transcendência, de uma "metafísica da presença" - em seus próprios termos -, que pela repetição pode ser capaz de fazer parecer que os processos de construção de verdade, isto é, de relação entre um termo e o que ele deve representar, sempre existiram, quando não passam de uma construção contingencial, arquivada, de modo a muitas vezes impedir sua revisão e questionamento. Não se trata de abolir todas as significações, mas de rever as condições de interpretação de certos sentidos, e de perceber o quanto eles em suas aplicações históricas são usados para a instauração de verdades opressoras, para além da própria linguagem.

No entanto, para o autor, a escrita, enquanto acontecimento, carrega por si só uma presença ao mesmo tempo pressuposta e contingente, ou seja, é aparentemente capaz de levar a outros momentos sentidos a eles talvez alheios e concomitantemente construir sua própria significação no tempo de leitura - o que atesta a ideia de iterabilidade apresentada por Derrida em textos como "Assinatura. Acontecimento. Contexto" (1991), a qual anuncia o quanto a repetição de um texto no tempo marca paradoxalmente sua singularidade a partir da contra -assinatura. Reproduzir, portanto, um texto ao mesmo tempo é marcar sua originalidade e retirá-la, pois pela leitura insere-se necessariamente nela um rastro de diferença, deslocando mais uma vez a perspectiva de 
que os sentidos da linguagem têm de ser em si um começo absoluto.

0 impasse primitivo da linguagem anuncia sua indecidibilidade. Indivíduo/ sociedade. Texto/contexto. A suposta clareza que atribui origens distintas para cada um desses termos, que pressupõe de antemão a separação de sua significação, traz a pretensão de uma metafísica cuja base é a dualidade. Entretanto, os próprios prenúncios comportam em si sintomas de uma construção mais contingencial que originária. Dentre as diversas relações em que essas separações apresentam-se, anunciam-se e nas quais há implicações que vão além da própria linguagem - ao mesmo tempo sem dela se desprenderem - estão as de aberto e fechado, que podem ser pensadas a partir da percepção de clausura, que em Derrida é aludida em diversos momentos enquanto uma condição do próprio processo de significação da tradição ocidental. ${ }^{2}$

Etimologicamente, o enclausuramento como uma espécie de fechamento, de encerro, do latim claudere, é em diversas vezes ressignificado em palavras que, mais do que anunciarem a condição de clausura, substantivam-na, como no caso de cela e de cárcere. A ideia de clausura como uma condição de privação em relação a uma abertura, a um lado de fora, é visível nesses casos. Da mesma forma, o claustro, cuja origem é a mesma de clausura, foi apropriado pelo Cristianismo para significar o pátio interior

20 autor afirma em Gramatologia que a história da metafísica, não apenas de Platão a Hegel, mas "fora de seus limites aparentes, dos pré-socráticos a Heidegger, sempre atribuiu ao logos a origem da verdade em geral" (DERRIDA, 2008, p. 4). Em Posições, o autor afirma em entrevista que seria preciso deslocar a partir da desconstrução essas oposições que formam a tradição ocidental "até o ponto de sua não-pertinência, de seu esgotamento, de sua clausura" (DERRIDA, 2001, p.13). de um convento, reiterando uma associação possível entre religião e fechamento, reclusão, atribuindo ao mesmo tempo a ideia de sacralidade à clausura. 0 termo clausura tendo atribuído um conceito de sacralidade à religião também poderia ser um movimento pensado, e isso levaria a ideia de fechamento a outros patamares, ao pensar a condição de privação a partir de um preceito positivo, tensionando o que se compreende conceitualmente como espaço fechado, como prisão, como limitação. Se caminhássemos por essa via, a de que a clausura é capaz de possibilitar acesso a um campo antes inacessível na condição de abertura, o encerro comportaria uma verdade singular e inapreensível de outra maneira. Em Vigiar e Punir (2008), Michel Foucault olha para a prisão como um encarceramento, uma clausura disciplinar, a qual tem por objetivo a transformação e o controle dos corpos dos indivíduos. Já em Cadernos do Cárcere, Antonio Gramsci (1999) vê a clausura como um recondicionamento emocional e político, capaz de dar outros sentidos ao pensamento. Isso, nas palavras de Roberto Vecchi, leva a uma pergunta pertinente do ponto de vista do processo de significação da condição de clausura: "que saber produz a cela"? (2010, p. 44).

Em Jamás el fuego nunca, Diamela Eltit (2012) apresenta a clausura, especialmente em termos políticos e de gênero, como resultado de outra temporalidade, construindo um determinado saber em certa medida relativo ao próprio enclausuramento. Isso se dá pela recordação da impossibilidade de sair da condição de encerro durante os anos de ditadura militar chilena, quando os movimentos de fuga e de esconderijo da narradora, enquanto parte de uma organização militante, limitaram-na por anos a pequenos locais. A narradora articula ao presente, 
no qual vive com um companheiro em um pequeno espaço, dividido entre quarto, cozinha e banheiro, uma representação imanente de um passado opressivo, que é transportado para o ato de narrar.

A ideia de pensar a clausura como uma possibilidade de pensamento, de produção de discurso, leva a uma reflexão sobre as contingências específicas que tornam a narrativa dessa condição possível. 0 fato, por exemplo, de memórias, esse eixo subjetivo e bastante espectral da condição humana, serem objeto de uma tentativa de escrita e de transferência à materialidade de uma obra já anuncia uma tensão a respeito do enclausuramento e do processo de significação das próprias rememorações. Se enquanto estrutura a obra em forma de livro é capaz de recuperar um pouco das condições da própria produção escrita - o próprio encerro -, ela também anuncia o quanto toda narrativa moderna tende a ser limitada à condição escrita-leitura individual. A literatura a partir de seus trâmites modernos, enquanto um espaço intensamente ligado à circulação do romance, à leitura individual, ao consumo de livros, aponta para uma relação intrínseca com uma perspectiva de mundo burguesa, cuja métrica é difícil de ser avaliada a partir de um único aspecto, mas que de todo modo funda alguns dos princípios liberais que levam a uma rearticulação daquilo que é definindo como algo que foge de uma lógica racional-científica, como os mitos, as lendas, os folclores, os ritos, a oralidade. Em alguma instância essa racionalidade implica, se pensarmos suas limitações e suas exclusões, também uma noção de clausura. A literatura, desse ponto de vista, poderia ser entendida como uma espécie de enclausuramento da narrativa seus autores, leitores, personagens, narradores circulam em suas próprias reclusões, em seus próprios mundos possíveis, em seus jogos e pactos ficcionais.

Ainda que essa afirmação já tenha sido em alguma medida tecida nas percepções de Adorno, como em seu texto "Posição do narrador no romance contemporâneo" (2008), ela colhe em si mesma a possibilidade de seu contrário: ao limitar-se, ao restringir o espaço da narrativa ao indivíduo, a literatura se libertaria e se democratizaria à medida que permite às suas narrativas explorar os mais variados espaços e inclusive colocá-los em xeque: a vida privada e os desejos de mulheres em Madame Bovary a partir de Flaubert, a possibilidade de reivindicação de escrita de mulheres em Um teto todo seu de Virginia Woolf - ainda que esse tipo de encerramento também tenha sido e ainda seja por vezes apontado como um risco à manutenção de certas estruturas em muitas instâncias concebidas como racionais, como as posições sociais de mulheres no século XIX, as instituições relacionadas ao casamento, a ideia burguesa de família, etc..

0 encarceramento da literatura, nesses aspectos, retoma a redoma sagrada já aludida anteriormente: o pátio de alguma forma religioso da escrita se tornaria um espaço do possível, de entrega, de redenção. No espaço da clausura também se acessaria um saber inacessível de outra maneira, isto é, as condições de produção da clausura, quando vividas e quando anunciadas em forma de narrativa, muitas vezes tornam possível tocar uma noção diferenciada dos limites da condição de existência e de presença, porque levam a lugares múltiplos, a inferências distintas. A clausura, portanto, limita, produz dor? Ou liberta, ao se apresentar como uma opção a círculos de abertura e de convivência que por vezes também podem ser extremamente limitados, limitantes e dolorosos? 
Em Amuleto, Roberto Bolaño (2017) aponta em alguma medida o quanto o espaço universitário pode ser capaz de abarcar também certa condição de enclausuramento e de proporcionar, ao mesmo tempo, tanto uma espécie de salvaguarda, de proteção, quanto de violação e de trauma. A universidade, na obra, é o espaço onde a clausura acontece. Ao longo da narrativa, há um paradoxo que manifesta o movimento da narradora Auxilio Lacouture pela cidade, pelo DF mexicano, em contraste com uma memória sobre a clausura vivenciada por ela durante 13 dias em um banheiro da Universidade Nacional Autônoma do México, um confinamento que lhe proporcionou se salvar da violência dos militares que tomaram o campus universitário em 1968 e que empreenderam o massacre de Tlatelolco na capital mexicana. Por outro lado, o encerro também pode ser visto como a motivação de uma cadeia de traumas, que configuram uma narradora cuja escrita é continuamente abalada por uma memória fragmentada sobre os dias em que passou presa no banheiro.

A visualização da clausura na obra enquanto essa condição de fechamento e de restrição, mas também, etimologicamente, como um local de recolhimento, serve em diversas medidas para encarar como as complexidades do espaço universitário contribuem também para tensionar as relações entre as noções de público e de privado, de aberto e fechado, binarismos que por si só apontam para uma série de outras dualidades, as quais comportam algumas das principais preocupações de Jacques Derrida.

Em "As pupilas da universidade" (1999), o autor alude ao espaço oculto que a busca por uma origem, por uma ideia de fundação, por uma razão de ser das instituições universitárias revela. Esse ocultamento parece justamente o movimento necessário para que a própria existência da instituição seja inquestionável, assim como suas práticas, hierarquias, saberes. 0 ato de não questionar a universidade é lembrado por Derrida (1999, p. 138) como um resultado de sua relação intrínseca, enquanto instituição moderna, com a ideia de um princípio de razão. No entanto, alude a Heidegger para pontuar que o princípio de razão nada diz sobre a própria razão. Qual seria a origem do princípio de razão? Qual o seu ponto de partida? Acrescenta a isso que nenhum fundamento, tal como o princípio de razão, pode fundar a si mesmo. 0 império da própria razão estaria então instalado justamente sobre um ocultamento, o ocultamento de uma suposta presença: a simples existência do ente universidade seria suficiente enquanto signo de uma essência que se pressupõe, o que todavia acaba por ressaltar a noção de "um fundamento cujo próprio fundamento permanece invisível" (Ibidem, p. 138).

Ao tratar do princípio de razão aplicado à estrutura universitária e enxergar nessa relação um mutualismo, Derrida retoma um aspecto fundamental à própria perspectiva de racionalidade ocidental, a perspectiva ontológica, que em sua visão, ao afirmar a primazia do ser, da presença, restringe a metafísica a uma espécie de clausura, como afirma em Posições (2001, p. 13). Já em Gramatologia, como visto, Derrida trata de um assombro em relação aos dualismos e de como a ideia de origem, de unidade e de propriedade de todo conceito funda a metafísica do Ocidente (2008, p. 4). Para ele, é necessário ir além dessa dualidade de significação pronta e pensar a escritura como um descompromisso com qualquer transcendência, com qualquer significado que lhe dê origem a priori e que lhe comande "de fora" de um contexto, ou seja, de fora do acontecimento próprio ao texto, de suas condições de produção. Isso coloca 
em xeque a primazia de uma origem, que daria um significado supostamente estável para um significante, e põe em destaque o próprio significante, o qual, por si só, seria capaz de ser a abertura para novos significantes, de comportar em si mesmo um significado, ainda que instável, escorregadio e desapossado, como um espectro.

A linguagem viraria um jogo de fantasmas, mas ao mesmo tempo tensionaria a desvalorização de eixos até então considerados secundários - e por isso mesmo vistos como menores, inferiores ou mesmo subordinados, não para inverter as hierarquias (mulher/homem; original/tradução, etc.) que muitas vezes se configuram nesses termos, mas para deslocar espaços e reivindicar um pensamento que vá além da dualidade, em que a fluidez dos conceitos escape a uma clausura da tradição, questionando, mais do que a oposição, a hierarquia que ela funda, baseada na anterioridade da origem.

Ao mesmo tempo em que fica evidente que a autonomia universitária é ferida e violentada, metonimizada na figura de Auxilio em Amuleto, também se pode supor que esse ente institucional nada comportaria de objetivo, de seguro, de inviolável, de uníssono - em certa medida demonstrando que o princípio de razão sobre o qual a universidade se funda está fadado à permeabilidade do jogo de forças que atua fora de uma perspectiva tida como racional (a violência policial $^{3}$, os ataques à pesquisa científica, o corte governamental de recursos). A intocabilidade da razão universitária, pelo contrário, é o tempo todo colocada em xeque já com a movimentação que, ano a ano, por exemplo, permite a entrada de novos estu-

3 Sobre a suposta "irracionalidade" contida em atos violentos, muitos debates têm sido tecidos a partir especialmente das considerações de Weber sobre o Estado Moderno e sua exclusividade coercitiva, como em WEBER (2000). dantes e de novos professores. Isso significa que a própria admissão e fluxo constante de discentes e também docentes indica uma movimentação constante entre o que está fora e o que está dentro do círculo universitário. Abstrair-se de todo esse amplo e variado jogo de forças convocando o princípio de razão parece apontar para o quanto se acredita na inviolabilidade desse princípio, na seguridade de sua origem. A demonstração de que o princípio de razão em inúmeros momentos foi utilizado para assegurar a manifestação de escolhas fora de um campo ético e democrático (bombas atômicas, testes em humanos e animais) revela, porém, que o signo "princípio de razão" justamente não contém em si uma origem assertivamente segura, mas que está o tempo todo e historicamente imbricado na relação com o que supostamente está do lado de fora da instituição.

Em Amuleto, a possibilidade de violação, de ser invadida por uma espécie de violência tida como irracional, demonstra a vulnerabilidade da estrutura universitária mesmo como um espaço assegurado pelos princípios basilares racionais. Pode-se pressupor, por um lado, que a autonomia universitária e sua desvinculação primária com o que se tece fora de seus muros dão a ela a força para a produção de conhecimento científico e para a primazia da razão, o exercício interno desses princípios e a possibilidade de expansão desses fundamentos para fora do espaço universitário em certos momentos. Por outro lado, ao projetar a produção de um conhecimento considerado científico, racional e superior como estritamente relativo ao espaço universitário, a universidade se fecha em si mesma, e tende a uma clausura que também prioriza aqueles grupos cujo acesso a essas estruturas é historicamente verificável. 
Ao se acreditar imune às próprias movimentações e transformações do que se chama princípio de razão, muitas universidades tendem, por exemplo, a não se abrir para o recebimento de estudantes a partir de cotas raciais. A Universidade de São Paulo, após anos de debates acirrados em torno desse tema, adotou as cotas apenas no vestibular de 2018, e conta com muitas resistências para a adoção de cotas raciais na pós-graduação e na contratação de docentes. $\mathrm{Na}$ contramão de outras universidades, não é irrelevante que a USP, considerada uma das maiores universidades da América Latina, comporte grande resistência a esse tipo de abertura. Sabe-se, e é importante reforçar, o quanto o termo universidade carrega aqui também seus conflitos: o fato de que os discursos produzidos sobre as cotas não sejam uníssonos é substancial. 0 que se destaca é que esse jogo de forças explora discursivamente o princípio de razão de maneiras distintas. Em algumas universidades, ele é vencido por quem quer conservar esse princípio com a defesa de que a abertura irá contaminar a manutenção de uma razão qualitativa (que as cotas piorariam a qualidade do ensino é um discurso bastante comum nessas instâncias). ${ }^{4}$ No entanto, se as métricas aplicadas a essas perspectivas já mostram o contrário, vale a pena ressaltar a complexidade do que se entende por avaliação da qualidade de um ensino, de uma pesquisa e de uma extensão.

Em “Timpanizar a Filosofia” (1991), Derrida trabalha com um princípio similar ao

4 Sobre esse assunto, ver levantamento feito pelo Insper: "As Cotas nas Universidades Públicas Diminuem a Qualidade dos Alunos Selecionados? Simulações com dados do ENEM", publicado em 2016 e disponível em: https://www. insper.edu.br/wp-content/uploads/2018/09/ Cotas-universidades-publicas-diminuem-qualidade-alunos-selecionados-ENEM.pdf (Acesso: 10/09/2020) que é apresentado em "As pupilas da Universidade", uma vez que o tímpano é trazido à tona como dotado de uma capacidade similar à de abrir e fechar da pupila. Ao comparar o pensamento ao tímpano, afirma que esse instrumento do corpo é como uma tela capaz de receber pressões, de equilibrar a pressão entre dentro e fora do ouvido. A partir de sua inclinação, essa espécie de membrana, para ele, fica suscetível ao lado de fora, e sua sugestão de timpanizar a filosofia tem relação com aumentar essa superfície de permeabilidade, para que a filosofia possa se abrir ao mundo. No entanto, a total permeabilidade também traz a surdez, o que destrói uma das possibilidades desse instrumento biológico: ouvir. No entanto, como considera Peter Pál Pelbart, em A Clausura do Fora e o Fora da Clausura (1989), esse encontro extremo entre o de fora e o dentro corre sempre um risco maior, o risco da loucura.

0 risco anunciado por Pelbart aponta para uma espécie de necessidade da clausura. Isso por que o enclausuramento parcial do pensamento, a limitação, o fechamento sensível parecem necessários para que a possibilidade do próprio pensamento aconteça. Para Pelbart, o pensamento na esteira do Fora é aquele que se expõe às forças do Fora, mas que mantém com ele uma relação de retorno, de tráfego, de viagem. 0 Pensamento capaz de acessar o Fora, como o tímpano para Derrida, arrisca-se num jogo com a Desrazão, do qual ninguém parece sair indemne ou ileso. A loucura seria, em sua visão, uma exposição total e sem mediação da zona de subjetivação a esse Fora. ${ }^{5}$

5 Em A nau do tempo-rei: sete ensaios sobre o tempo da loucura, Pelbart afirma que "Para Deleuze, a característica maior desse Fora é a de consistir no Jogo de Forças, do Acaso e do Indeterminado, ao qual temos acesso sempre historicamente, isto é, segundo estratificações de Saber, diagra- 
No caso da universidade, a timpanização parece um exercício de manutenção da atenção à abertura e da reivindicação de um trânsito, da consciência a respeito de um movimento. Fechar-se completamente pode criar uma espécie de pressão do lado de fora que seja, mais do que tudo, destrutiva de toda a instituição. Por outro lado, abrirse completamente é eliminar a importância da reclusão para a reflexão, a elaboração e reelaboração de métodos, os quais podem permitir uma estrutura que de fato caminhe na esteira de uma ética democrática. Em "As pupilas da Universidade", a alusão a relações internas e externas à universidade convoca, no texto, uma responsabilidade nesse sentido. Isso ocorre porque, ao mesmo tempo em que investigar a razão desse princípio de razão que funda a universidade parece necessário para que se repense uma responsabilidade a ela relativa, também corre-se o risco de esse caminho ser interpretado como irracional e obscurantista, pois coloca em questão a própria ideia de princípio de razão enquanto um mantra defensor de ritos, práticas, discursos e saberes internos à universidade. Para Derrida, porém, não se trata de cair num irracionalismo, mas de buscar uma espécie de comunidade de pensamento que seja capaz de trazer à cena "lugares múltiplos, postulações móveis, ritmo estratégico" (DERRIDA, 1999, p. 151), ao se pensar tanto as pesquisas quanto os profissionais e as ideias de profissionalização associadas a esse espaço. Corre-se o risco de que forças sociopolíticas capazes de descaracterizar o princípio de razão como um todo se apro-

mas de Poder e modalidades de subjetivação determinadas. Na loucura, o sujeito ficaria exposto sem proteção alguma à violência desse Fora, e sem condições de estabelecer com ele um vaivém ou uma relação. Abertura máxima ao Fora, e ao mesmo tempo extravio no temporal abstrato, que é sua marca" (PELBART, 1993, p. 97). priem dessa tentativa de responsabilidade, mas é um risco que precisa ser enfrentado com atenção e vigilância, para o filósofo. A universidade, portanto, deve ser cuidadosa em relação ao que abre ao mundo, mas também em relação ao que fecha em si, afirma Derrida. Talvez esse seja um caminho para pensar o futuro dessa instituição e do próprio pensamento, alçando-os ao acaso, como a todo porvir, mas invariavelmente também à memória acerca de seus princípios.

Em "Essa estranha instituição chamada literatura" (2014), Derrida demonstra em certa medida quanto o artifício literário fornece a ele a oportunidade de pensar o impensável: o anacronismo que funda as relações no mundo. Para o autor, o texto literário se apresenta anacronicamente, desgarrado, e essa complexidade histórica de um evento pode ser o que permite sua leitura em seu próprio contexto e fora dele. Ao pensar esse caminho, Derrida dialoga com o quanto muitos escritores seriam capazes de um certo movimento de timpanização do pensamento, isto é, de acessar o Fora e trazê-lo para o contexto da escrita, permitindo esse trânsito. Para Derrida, Kafka e Joyce são uma espécie anacrônica em seu tempo e fora dele, tal como Shakespeare e Blanchot, por exemplo.

Essa observação se relaciona com a perspectiva analítica de Jacques Rancière em $O$ inconsciente estético (2009), em sua tentativa de correlacionar o pensamento de Freud a respeito do inconsciente ao que chama de a virada estética na literatura - a qual teria abandonado uma perspectiva representativa da arte fundamentada no princípio aristotélico de ação e de história, em que as narrativas seguiriam um princípio causal e sequencial que manifestariam e atestariam 
uma realidade histórica e factível. Essa virada traria à tona uma literatura capaz de operar fundamentalmente no detalhe, na obscuridade, no não-dito ou no que se oculta.

A busca por uma autonomia do pensamento estético em relação à história e à representação do real dialoga com o fato de que, para o filósofo, essas obras de arte "são os testemunhos da existência de certa relação do pensamento com o não-pensamento, de certa presença do pensamento na materialidade sensível, do involuntário no pensamento consciente e do sentido no insignificante" (RANCIÈRE, 2009, p.10-11). Isso contribuiu, de acordo com o autor, para firmar uma tradição analítica do detalhe, que pela literatura parecia contribuir para se acessar ou mesmo expressar os dados que sustentam a relação imanente e intrínseca entre pensamento e não-pensamento, a profundidade das ações e dizeres, assim como os "signos mudos" e as "palavras surdas". Aqui pode ser visto aquilo a que Pelbart chamou de trânsito, a trajetória que o artista seria capaz de empreender.

Esse espaço denominado "inconsciente estético", que abarcaria toda essa relação possível sobre o que se é, seria o que permitiu a Freud também ter um campo profícuo com o qual se relacionar. 0 artista analista, como Balzac, ao atuar nesse inconsciente estético de suas personagens e tramas, seria tão cientista quanto Freud. Aí residiria outra consciência a respeito de ciência e cultura, assim como aí residiria, justamente, outra consciência a respeito do real e do fantasioso, do histórico e do mítico, que Freud tanto reivindicou como matéria do pensamento científico. A arte, assim, teria se tornado um espaço que, correlativamente à psicanálise, e mesmo antes desta, assumiu as esferas do detalhe insignificante e o tratou como parte de uma realidade mais ampla e não apenas dizível e visível sobre o indivíduo. 0 detalhe que não é explicável poderia permanecer não explicado.

A reivindicação da literatura como esse trânsito aponta, no entanto, para distintas problemáticas: uma se relaciona com o fato de o próprio tráfego - o contato com o inexplicável, a loucura - se tornar uma espécie de universalidade literária. Isso significaria eliminar do curso artístico reconhecido tudo aquilo que não empreende esse trânsito, ou que o omite demais, ou que o escancara demais. Porém, a ausência desse tráfego, ou de sua materialização crítica, tornaria a obra "menos literária"? Isso tornaria a desrazão ou a razão plena excessos desnecessários para o exercício equilibrado de uma suposta literariedade?

Diamela Eltit durante décadas foi lida como uma autora cujo pressuposto era a vinculação a uma militância política e de gênero. Nesses âmbitos, a relação de significação em suas obras acaba por ser bastante enclausurada. ${ }^{6}$ Roberto Bolaño, no entanto, tem sido lido como um signo de universalidade, ao supostamente garantir esse trânsito, mesmo por vezes de maneira bastante irônica, equilibrando seus próprios desafetos com a teoria e a crítica literária, mas sem delas se desvincular. ${ }^{7}$ Esse não per-

6 Na organização Diamela Eltit: redes locales, redes globales (2009), Rubí Carreño traz à tona questionamentos acerca de como ler Eltit após quase uma década de virada de século e, em “¿Qué eres? Una torpe, alerta, alarmada, fronteras?", vê um grande perigo em leituras que se baseiem apenas na relação da chilena com a ditadura e o feminismo, que considerem-na como uma "profeta del margen" (Ibidem, p. 14), reivindicando leituras que se predisponham a analisar os trabalhos de Eltit a partir de métricas que não sirvam para enclausurá-la.

7 Sobre isso, Bolaño Salvage (2008) traz à tona artigos que versam sobre as inserções do autor em uma perspectiva comparativa extra-chilena, em textos que o inserem até mesmo em uma possível tradição argentina à esteira de Borges e Cor- 
tencimento, percurso escorregadio, é visto muitas vezes como um trânsito celebrável. Por outro lado, o identitarismo, a referencialidade, um explícito engajamento são vistos como datados e não aptos a uma contra-assinatura num outro tempo. Ler Mano de obra, de Eltit (2004), daqui a cem anos pode parecer impossível pela especificidade da lógica tediosa e massificante de trabalho em um supermercado que a narrativa traz, a qual nessas primeiras décadas de século XXI ainda parece bastante latente. Noutra perspectiva, o espírito detetivesco enquanto forma, de um Bolaño de Los Detectives Salvages (1998) e Monsieur Pain (1999), é algo que parece dialogar com uma tradição que vem ao menos desde Poe e soa apta a atravessar o tempo.

Porém, a condição de pertencimento a um tempo histórico e à clausura dessa manifestação como um eixo limitante à circulação posterior dessa obra e à sua repetição no curso do tempo talvez apontem não para o que há de similar entre passado, presente e futuro, mas justamente para o outro que o próprio presente se tornará, condição indispensável para o porvir. Eltit, além de deixar seus próprios rastros de diferença, é por si só um eixo da condição de produção de um agora, que em alguma medida proporciona a obras como as de Bolaño uma perspectiva supostamente universal. ${ }^{8}$ Aqui, ao

tázar. Ao tomar como parâmetro a transição do autor entre Chile, México e Espanha, assim como suas críticas constantes às ideias de nacionalidade, o compilado traz análises que também consideram Bolaño como articulador de um cânone próprio e pessoal, tendo em vista a desmistificação de hierarquias e a consideração de outras, que pareciam levar à sua própria inserção em um cenário literário mundial, como aponta Cecilia Manzoni, em "Ficción de futuro y lucha por el canón en la narrativa de Roberto Bolaño".

8 Na parte final de 2666, Bolaño (2010) apresenta um vendedor de máquinas de escrever que dedica algum tempo de sua fala para tratar da relação mesmo tempo em que se coloca em xeque a universalidade por ora trazida por Derrida em "Essa estranha instituição chamada literatura”, arrisca-se sua correlação intrínseca, e portanto impossível de ser abandonada, com o local, que ele mesmo contribuiu para se trazer à tona ao pensar a necessária recomposição dos processos de atribuição de sentido e dos dualismos hierarquizantes que eles carregam.

Assumir um universal não precisa, portanto, ser sinônimo de qualificação, assim como "original" em relação a "cópia", como "homem" em relação a "mulher". Da mesma forma, a própria ideia de universalidade é posta em questão quando se percebe que é impossível que uma obra seja de todo universal, uma vez que esse pressuposto de inúmeras maneiras se apropria do que é concebido como singular em diversas outras realidades. Não significa que Bolaño por si só alcance universalidade ao extrapolar, em alguma medida, certa localidade, justamente porque a significação de universalidade pode ser vista a partir de outras significações e inclusive caracterizar especificidades, como em El cuarto mundo, de Eltit, no qual o universo de ação e pensamento do narrador está intimamente ligado ao ventre de sua mãe e ao círculo privado de sua família. A capacidade de uma obra de se projetar

entre obras ditas "maiores" e obras "menores", afirmando que as obras-primas são um bosque, mas que um bosque necessita de pinheiros, musgos, etc, para de fato ser um bosque. A consciência a respeito de um mutualismo entre as obras da literatura mundial soa relevante, justamente por ser marcado ora por uma espécie de valorização de umas em detrimento de outras, ora por rechaçar os valores acadêmicos e canônicos atribuídos à literatura. A ironia em questão mostra o modo como esse rechaço estrutura de alguma forma o modo como a literatura é vista em Bolaño, ao mesmo tempo em que denuncia sua própria condição de pertencimento e de despertencimento em relação a um cânone que o precedeu. 
como uma representação que vai além de seu local e de seu tempo soa como um imperativo que não se verifica se se entende a formação da significação como contingencial e ligada a um movimento de contra-assinatura. Nesses casos, quem contra-assina os textos aos quais creditamos universalidade? Os termos, caros por si só a uma definição, comportam em si descontinuidades que vão além da própria linguagem.

Para Derrida, a literatura como essa instituição - paradoxalmente - universal seria também o que permitiria extrapolar, desafiar, suspender a lei - inclusive a lei que supostamente funda os princípios de razão -, pois ali se pode dizer tudo, ali está tudo por dizer. Essa suposta universalidade, entretanto, leva a perguntas como: pode-se mesmo dizer tudo na literatura? Acessar o Fora - o espaço onde a ideia de alguma ética é muitas vezes (ou totalmente) ausente, onde a razão a respeito de direitos e de legitimidades talvez não se alcance - e retornar a uma clausura do pensamento são movimentos complexos de se identificar e de se julgar. Isso anuncia, por ora, a própria rasura de uma determinação que se fixe apenas no texto, mas também, por outro lado, condena uma que se fixe apenas no contexto. Ao contrário: não haveria algo fora desses dois espaços, na visão de Derrida.

Como consequência dessas reflexões, a relação entre esses caminhos parece, portanto, mais simultânea do que a princípio se teorizava. As próprias condições de leitura e de contra-assinatura também servem para significar o quanto os sentidos são móveis e necessariamente contingentes - o caso de livros de Monteiro Lobato comportarem racismo é emblemático. Ler suas obras na atualidade é um movimento de contra-assinatura também marcado pela diferença das condições de produção e de leitura do tem- po presente. Reproduzir o texto sem essa marca de diferença, sem o rastro do leitor que assina agora, é situar o passado como um país estrangeiro. Isso, no entanto, não resolve o impasse, mais do que necessário, a respeito de quanto o presente é a possibilidade justamente de um movimento ético de iterabilidade desses discursos. Tal perspectiva de iterabilidade atesta tanto a singularidade do texto em questão quanto sua permeabilidade ao processo histórico que o sucedeu, eliminando por ora a transcendência de um significado e de uma presença nos significantes empregados naquela escrita. Mostra-se, assim, de alguma maneira que a escrita não é, somente, a capacidade de se transportar para um outro tempo - que por sua vez também não era homogêneo, uma vez que a contemporaneidade própria a Lobato já apresentava resistências a discursos racistas, como na obra de Lima Barreto - mas que essa capacidade comporta em si todas as contingências de uma leitura outra, de uma leitura do outro, de um outro de outro tempo, que ao assinar confirma e ao mesmo tempo nega, que ao assinar reproduz e ao mesmo tempo deixa sua marca de contra-leitura.

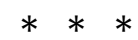

A clausura em Bolaño, em Eltit, na universidade, a clausura violenta, a clausura que permite o pensamento, que possibilita a proteção, que protege o outro. A clausura só. A clausura com alguém. A condição de clausura daqueles que fazem do confinamento uma espécie de espaço de fora para uma clausura de dentro, para acessar o que está em alguma medida no pensamento, na possibilidade de se enclausurar de sua própria clausura e abrir espaço para outros tipos de silêncio; a condição de clausura daque- 
les que estão em família, que reorganizaram os espaços internos do lar para o exercício ora individual ora conjunto do estudo, do trabalho, da limpeza, do ato de cozinhar; a condição de clausura daqueles que estão com animais, com gatos e cachorros, cujas companhias apresentam outra dimensão sobre silêncio e fala; a condição de clausura de quem precisa sair para trabalhar, e que portanto olha para a clausura alheia como algo inacessível, como um espaço de privilégio; a condição de clausura de quem está em outro país; de quem está preso e não pode receber visitas; de quem dependia da não clausura dos outros para sua subsistência; de quem ficou doente ou viu alguém morrer porque outra pessoa não respeitou sua clausura; de quem se deprime por estar só; de quem se entedia e recorrentemente sai à rua sem proteção porque deprecia a clausura. A condição de clausura do próprio conceito de clausura.

A contingência do agora, do tempo presente deste texto, as distintas experiências com a clausura são as mesmas que anunciam a impossibilidade de traduzir o acontecimento em um único termo. São agora necessários outros nomes para a clausura? As variadas significações numa mesma língua formam as mais difíceis traduções, sugere Derrida, ao tratar da tradução nas entrevistas de Posições (2001). Uma palavra é sempre outra, portanto. Desconstruir o termo clausura parece justamente o movimento que anuncia o quanto o significado que se considera, a priori, como original, primário, independente, autônomo, é na verdade também o contrário. Essa precariedade dos conceitos, entretanto, revela uma possibilidade bastante significativa das experiências no campo dos acontecimentos, que têm relação com a abertura para a incorporação do outro, do estranho, do inesperado. Se se inter- preta a filosofia ou a universidade como um campo em certa medida hermético, racional, estável, anula-se a possibilidade de tudo o que em outros processos de significação não abarca essas adjetivações.

Não se trata de negar a importância da aplicação de pesquisas na sociedade - o mesmo vale para a literatura, ao afirmar que não se trata de negar a relação entre o texto e o que supostamente está fora dele, como mercado editorial, compromisso político, etc. -, mas de entender o quanto tanto o que está na universidade e no texto quanto o que está fora configuram um exercício contínuo de observação, de assunção das capacidades móveis do tímpano e da pupila, que visam a equilibrar a sobrevivência do órgão em questão e mesmo do organismo.

A entrada de um álbum dos Racionais MC's na lista de leitura do vestibular da Unicamp parece justamente ilustrar esse movimento, tanto no campo da literatura, quanto no da universidade: opta-se por certo contato com a cultura do rap como parte dos requisitos necessários para se adentrar a universidade em convivência com obras como a de Camões, que ressaltam certa tradição de leitura ocidental; ao mesmo tempo, coloca-se o álbum como obra literária, como apto (com seus conteúdos e formas) a conviver em um espaço historicamente marcado pela defesa de uma certa tradição formal, aludindo a uma possível permeabilidade da literatura.

Da mesma forma que esses deslocamentos ocorrem na esteira de ambas as instituições, não se pode deixar de abordar o quanto eles também ocorrem na esfera do próprio rap. Ser visto como literatura para ser reconhecido e legitimado também instaura um jogo de forças que anuncia a preocupação com um gênero que a ele é próprio, com um acontecimento que não se resume 
ao literário. Ángel Rama (2001) veria esse processo de literarização de manifestações populares como transculturação. Por outro lado, a celebração desse acontecimento pode esconder os aspectos hierárquicos e de relações de poder aferidos ao campo literário em detrimento de outros tipos de manifestações. Marcos Natali (2006), ao observar esse tipo de processo, sugere que ocorre o que se poderia compreender como uma síntese que neutraliza forças marginais. Aqui, entram em xeque diversas questões, como a ideia de universalidade vista nas projeções de movimento da literatura, a partir de Derrida, Rancière e Pelbart. Entretanto, a partir também do próprio Derrida, pode-se ver que a perspectiva de uma universalidade é totalmente dependente de localidades específicas. 0 rap, enquanto espaço dotado de complexidade, também está sujeito a esse jogo. Ao mesmo tempo, reduzi-lo a um projeto de identitarismo ou de simples compromisso político é negar as diversas possibilidades de linguagem ali presentes, é enclausurá-lo numa dinâmica referencial que pode servir apenas para controlar seus possíveis efeitos, a partir do que se pensa estar sendo dito.

Isso significa que a literatura, para além de definições enclausuradas - seja ela vista como em contraste e em relação ao rap, ou vista como literatura juntamente com o rap -, é em grande medida um espaço de permeabilidade, cuja definição é mais do que tudo escorregadia. Essa afirmação, no entanto, não pode implicar irresponsabilidade a respeito de seus efeitos e condições. Pelo contrário, é justamente pelo fato de ser um espaço tensionado, despertencido e espectral que a demanda por olhares cuidadosos a respeito das relações de poder a ela inerentes precisa ser talvez ainda maior. A pupila permanece, assim como o tímpano.
Os exercícios distintos de observação, de abertura e de fechamento, demonstram que a restrição a apenas um deles pode servir a um processo de limitação (ou de universalização) daquilo que ao corpo (ou à literatura, ou à universidade, ou à linguagem) é próprio.

As permeabilidades, nesse sentido, passam por diversas vias de cada um desses organismos. Parece, portanto, um processo pelo qual passa toda a significação, a linguagem e a própria condição do que se entende, em alguma medida, humano. A clausura, etimologicamente, caracteriza uma vez mais essa possibilidade, ao se relacionar com as origens de cárcere e ser associada à raiz latino-germânica de skark, de sacer, que significa separado, termo utilizado por Giorgio Agamben (2017) para pensar a perspectiva em certa medida sagrada de ser humano, ao propor a noção de Homo sacer em contraposição a uma precarização da vida na contemporaneidade. Em diálogo com Heidegger, a relação entre ser separado e diferenciado é pensada por Agamben como uma contraposição a um suposto automatismo animal. ${ }^{9} \mathrm{O}$ humano estaria para o Aberto, e o animal para a clausura do pensamento. Para os filósofos, a redução do humano a esse automatismo tem se dado por meio de tecnologias políticas que impedem homens e mulheres

9 A perspectiva de Heidegger a respeito desse automatismo animal pode ser vista quando ele afirma que "Animais domésticos são mantidos em casa por nós, eles "vivem" conosco. Mas nós não vivemos com eles, se é que a vida significa: ser sob o mesmo modo de ser do animal. Não obstante, estamos com eles. Este ser-com também não é, contudo, nenhum coexistir, uma vez que o cachorro não existe, mas apenas vive. [...] Nós dizemos: o cachorro está embaixo da mesa, ele sobe a escada. [...] Ele devora seus alimentos conosco - não, ele não come. Porém, esta comunhão conosco! Um acompanhamento, uma transponibilidade - e, todavia, não" (HEIDDEGER, 2006, p. 242). 
de exercerem o "ser-aí" no mundo. 0 animal apenas subsistiria, seria o "ser vivo", assim como os seres inorgânicos seriam um "ser dado" em seus ambientes. Para Agamben, a contemporaneidade animaliza e empobrece o ser humano, tira sua perspectiva ontológica. Essa presença alude a uma significação já pressuposta, que leva a pensar uma vez mais os dualismos a partir da clausura da linguagem, mas também de seus resultados para além dela. 0 que é o animal? 0 que há nele que proporcione dizer que um suposto automatismo o caracteriza, e que se reduzir a isso implica barbárie? A relatividade desses conceitos, de suas representações e apreensões culturais pode ser vista sob pontos de vista culturais bastante particulares. $\mathrm{Na}$ ambiguidade da relação humano-animal na tradição judaico-cristã, por exemplo, essa assimilação se dá como queda e dádiva; maldição e transcendência.

Sabe-se que a clausura animal - seja fisicamente, seja no fato de serem supostamente incapazes de se comunicar - é recorrente numa perspectiva ocidental, em que tais seres são tratados como aptos a serem escravizados por uma cultura que necessita de seus corpos e de sua força - e aqui se pode inclusive questionar a perspectiva de força de trabalho - especialmente a partir da lógica capitalista. Se refletir sobre suas próprias limitações é o que caracterizaria, em certa medida, o humano, como propõe Agamben, como explicar as constantes perspectivas de destruição ilimitada da noção ocidental de vida? Ou, como coloca Achille Mbembe (2016), apenas alguns tipos de vida são escolhidos para serem sacrificados? 0 filósofo foca na perspectiva racial e esboça pontualmente a relação com o animal, cabendo reforçar a ideia de uma necropolítica que também dê conta do animal não-humano, que é escolhido em condições bastante es- pecíficas e projetadas para a morte, banalizada do ponto de vista industrial e submetida a uma validação significativa do ponto de vista linguístico, que inclusive se relaciona com o caminho oposto: a animalização do corpo negro, uma vez que ser animal seria símbolo de uma aptidão à opressão. Entretanto, a clausura animal - isto é, sua incapacidade de se projetar no Aberto analisado por Agamben - não pode ser, como as outras clausuras, uma espécie também de salvaguarda? Se por um lado as ideias de Marx (2017) sobre o trabalho contribuem para caracterizar parte da dignidade humana em relação a outros seres, por outro, as horas vadias, de descanso, de ócio e de lazer também entendidas como horas animais -, seriam nossa única chance de humanização no capitalismo.

Separar, nesse sentido, o humano não-animal do humano animal é negar uma correlação de forças biológicas e culturais, negar a permeabilidade intrínseca ao que se concebe como ser humano, negar o fato de os seres humanos serem por si só uma extensão, uma matéria composta de infinitas matérias vivas. Acreditar que o humano, diferentemente de correlacionado a outros seres, é de fato um ser enclausurado, cuja vida independe biológica e culturalmente de outras vidas, não é justamente ir em direção a um automatismo? Talvez os resultados muito bem considerados por Agamben sobre campos de concentração, sobre dominância e controle biopolíticos, não tenham relação justamente com o fato de os seres humanos negarem suas permeabilidades como inerência? Considerar o animal um ser - condicionado a supostas clausuras biológicas e a pretensas clausuras ambientais (prendê-los a correntes, currais) - incapaz de nos afetar parece servir a uma projeção de eliminação de esteiras de 
vida que escorreguem na compreensão que temos de existência, vidas com detalhes que permanecem inexplicáveis dentro do princípio de razão de nosso entendimento e comunicação. Enclausurar animais para o consumo e também para a convivência indica que o que entendemos por humanização em certa medida depende dessa relação de dominação.

Heidegger e Agamben, na esteira da consideração da linguagem como "essencialmente" humana, ao vê-la apropriada pelas tecnologias, caracterizam os humanos como "entediados" e fadados ao niilismo, conceitos atribuídos por eles a uma animalização do ser. No entanto, a alusão negativa atribuída ao animal, mais do que revelar alguma problemática em relação à condição humana na contemporaneidade, contribui para se encarar a aproximação entre humanos e animais como uma ameaça a uma suposta superioridade daqueles em relação a estes. A visão dos filósofos, nesse momento, ressalta uma perspectiva antropocêntrica que invariavelmente vem contribuindo para um mal-estar de ambas as espécies.

Não seria possível que dessa esfera chamada niilista (como a própria desconstrução foi acusada) surgisse uma perspectiva de diferenciação que não precisasse pressupor uma essência? Dentro da lógica de Marx, o capitalismo seria um espaço fundacional para a chegada a uma sociedade sem separações hierárquicas, cujas essências de superioridade, interpretadas sob critérios universalistas, não mais fossem louvadas. Esse suposto niilismo está apagando a essência do humano ou apenas acendendo a presença de grupos que por tempos não foram contemplados com essa máxima da dignidade, da sacralidade? Em $O$ animal que logo sou (2002), Derrida aponta o quanto o animal, diferentemente da perspectiva de
Agamben e de Heidegger, pode ser o outro que nos olha e que é condição para nossa própria existência. 0 outro, esse estrangeiro que nos suporta, que nos comporta e que nos permite a individualidade e a experiência de comunidade, é também o que carrega o detalhe incompreensível, a comunicação $a$ priori interrompida.

A clausura enquanto condição imposta ao animal talvez diga menos sobre suas capacidades de comunicação e de sentir do que sobre nosso próprio enclausuramento ante o diferente, sobre uma suposta transcendência que parece uma vez mais centralizar-se numa metafísica da presença, mas de uma presença específica: humana, racional, objetiva, masculina, branca. As inúmeras facetas da clausura, no entanto, apontam para a correspondência necessária e aparentemente inerente entre o eu, o outro, mas também para com o outro do eu, o outro do outro. 0 suposto paradoxo desse processo talvez anuncie uma ironia ainda maior, a de que numa condição de clausura, que proporcione o espaço para a reflexão ou mesmo para a salvaguarda, é o outro, muitas vezes visto como inimigo, que proporciona o espaço, a roupa e o alimento para a sobrevivência - os carcereiros, mas também entregadores, operários, que ganham a característica inimiga ao serem, por exemplo, alvo cotidiano de racismo. A clausura, nesse sentido, talvez seja o espaço da hospitalidade de que fala Derrida: acolher quando isso parece impossível; responsabilizar-se pelo que não é meu. Assim, se, como todo arquivo, a pulsão de destruição coexiste com a de criação, todo aberto é uma prisão, mas qualquer prisão é, inevitavelmente, também um aberto. E isso, mais do que acolhedor, é também uma promessa. Como a própria escrita, comporta sempre uma ou mais dúvidas, sempre um ou mais fantasmas. 


\section{Referências}

ADORNO, Theodor. Notas de literatura I. São Paulo: Editora 34, 2008.

AGAMBEN, Giorgio. 0 Aberto. 0 homem e o animal. Rio de Janeiro: Civilização Brasileira, 2017.

BOLAÑO, Roberto. 2666. São Paulo: Companhia das Letras, 2010.

Español, 2017.

Amuleto. Barcelona: Vintage

Los Detectives salvages. Barcelona:

Editorial Anagrama, 1998.

. Monsieur Pain. Barcelona: Editorial

Anagrama, 1999.

DERRIDA, Jacques. "As pupilas da Universidade".

In:

. 0 Olho da Universidade. Tradução

de Ricardo Iuri Canko e Ignacio Antonio Neis. São

Paulo: Estação Liberdade, 1999, p. 123 - 157.

"Assinatura. Acontecimento.

Contexto". In: Margens da filosofia.

Tradução de Joaquim Torres Costa, Antônio M. Magalhães. Campinas, SP: Papirus, 1991.

Essa estranha instituição cha-

mada literatura: uma entrevista com Jacques Derrida. Tradução de Marileide Dias Esqueda. Belo Horizonte: Editora UFMG, 2014.

. Gramatologia. Tradução de Míriam Chnaiderman e Renato Janine Ribeiro. São Paulo: Ed. Perspectiva, 2008.

Editora da Unesp, 2002.

0 animal que logo sou. São Paulo,

.Posições. Tradução de Tomaz Tadeu

Lima. Belo Horizonte: Autêntica, 2001.

"Timpanizar a filosofia". In: Mar-

gens da Filosofia. Tradução Joaquim Torres Costa, Antônio M. Magalhães. Campinas, SP: Papirus, 1991.

ELTIT, Diamela. Jamás el fuego nunca. Espanha: Editorial Periférica, 2012.

Tres novelas. México: FCE, 2004.

FOUCAULT, Michel. Vigiar e Punir: nascimento da prisão. Tradução de Raquel Ramalhete. Petrópolis, RJ: Vozes, 2008.
GRAMSCI, Antônio. Cadernos do cárcere. Tradução de Carlos Nelson Coutinho. Rio de Janeiro: Civilização Brasileira, 1999.

HEIDEGGER, Martin. Carta sobre o humanismo. Lisboa, Guimarães, 1987.

Os conceitos fundamentais

da metafísica: mundo, finitude, solidão. Rio de Janeiro, Forense Universitária, 2006.

MANZONI, Cecilia. "Ficción de futuro y lucha por el canón en la narrativa de Roberto Bolaño". In: SOLDÁN, Edmundo Paz; PATRIAU, Gustavo Faverón (orgs). Bolaño Salvage. Barcelona: Candaya, 2008.

MARX, Karl. Manuscritos Econômico-Filosóficos. Tradução de Luciano Cavini Martorano. São Paulo: Martin Claret, 2017.

MBEMBE, Achille. Necropolítica. Artes \& Ensaios, v. 32, 2016, p. 123-151.

NATALI, Marcos. “Além da literatura”. In: Literatura e Sociedade, 11(9), 30-43. Disponível em: https:// doi.org/10.11606/issn.2237-1184.v0i9p30-43 Acesso em 10/09/2020

PELBART, Peter Pál. A nau do tempo-rei: sete ensaios sobre o tempo da loucura. Rio de Janeiro: Imago Ed., 1993.

Da Clausura do Fora ao Fora da Clausura. São Paulo: Brasiliense, 1989.

RAMA, Ángel. "Os processos de transculturação na narrativa latino-americana". In: Flávio Aguiar e Sandra Guardini Vasconcelos (orgs.). Ángel Rama: Literatura e cultura na América Latina. Trad. Rachel La Corte dos Santos e Elza Gasparotto. São Paulo: EDUSP, 2001.

RANCIÈRE, Jaques. 0 inconsciente estético. São Paulo: Editora 34, 2009.

VECCHI, Roberto. "Alegorias claustrosóficas: o pensamento confinado, a exceção e a história literária." In: Rassegna iberistica 91, 2010, p. 43-52.

WEBER, Max. 2000. "Política como Vocação". In: Ciência e Política: Duas Vocações. São Paulo: Cultrix, 2000, pp. 55-124.

Recebido em: 15/10/2020 Aprovado em: 15/11/2020

Esta obra está licenciada com uma Licença Creative Commons Atribuição 4.0 Internacional. 